\title{
Evaluating Saudi Corporate Companies Online Recruitment
}

\author{
Tahreem Noor Khan ${ }^{1 *}$ \\ ${ }^{1}$ Al Yamamah University, Riyadh, Saudi Arabia \\ *Tahreem Noor Khan, E-mail: tahrimnoor@hotmail.com
}

Received: January 28, 2017

Accepted: February 15, 2017 Online Published: February 17, 2017

doi:10.22158/jbtp.v5n1p9

URL: http://dx.doi.org/10.22158/jbtp.v5n1p9

\begin{abstract}
Organisations are already using their corporate website to advertise jobs and receive resumes online. However the matter of question is how efficient is the web features and e-recruitment process? This research evaluates job opportunities advertised at Top Ten Saudi companies listed in February 2016. Factors evaluated on company webpage are: Navigation (career link), Job advertised (updated and information), nationality and gender focus for advertised job, information about company values on career page, process for filling application. These criteria were evaluated as they are the key determinant factors to identify efficiency and functionality of a webpage. Furthermore, it will assist to understand trend for pooling applicants in Saudi context. Based on concise review of online recruitment practices, it was possible to suggest ways on empowering and usability of e-recruitment method for Saudi companies.
\end{abstract}

Keywords

online recruitment, E-recruitment, Saudi Human Resources Management

\section{Introduction}

Due to Saudiazation policy in 2011, organisations are encouraged to hire and support Saudi nationals at work. As a result, it becomes a challenge finding qualified Saudi candidate with right skill. Challenges was there while implementing national policy, few businesses adopted fake Saudiazation, and some businesses were close down for not meeting quality and competency of expats (Peck, 2014; AlSheikh $\&$ Erbas, 2012). Issue arises further with lack of individual effort in finding job, Saudi workers either prefer bureaucratic managerial jobs or they rely on government support (Al Maeena, 2016). Another sad fact is that huge public funding has gone into education in Saudi Arabia but graduates cannot find jobs. Insufficient information flow between different labour and education sector contribute further to problem, thus require more synergized and aligned efforts in identifying future job requirements of the economy (Al Sheikh, 2015). The availability of up-to-date and complete information on job seekers and potential employers in the public and private sector would be an important element of managing labour efficiently (Al Asmari, 2008).

In such scenario, attracting right candidate is essential, for that the most cost efficient method of pooling suitable candidate is e-recruitment also job seekers prefer to use e-recruitment for a vacancy searching (Bharwani \& Butt, 2012; Allen et al., 2007).

But the matter of question is:

- How Top Ten Forbes listed Saudi corporate websites advertise jobs? (easy to navigate, sufficient information provided about job, organization, gender/nationality, updated job page frequently, process of application through website)

- What elements of Saudi e-recruitment should be focused and improved? 


\section{Literature Review}

Exploratory and Qualitative research approach is selected for this research therefore articles, research papers related to e-recruitment and website have been focused in this regard.

\subsection{Processing Application Fast}

In a digital world, the prevalence of internet provides significant and advantageous ways to enhance organisational recruitment practices. E-recruitment is possible through corporate web site or jobs boards (such as monster.com) for posting job advertisements (Gregory et al., 2013). Evidence suggests that half of new hires originate from the internet, with significantly reducing advertising costs and by reducing recruitment related administration process (Gregory et al., 2013; Cober \& Brown, 2006; Maurer \& Liu, 2007; Grensing, 2004). Job advertisement appears immediately on website and can remain long as the recruiter requires it. Furthermore, screening of application and despatching of $\mathrm{CV}$ to managers is also possible within short time.

\subsection{Clarity of Information Concerning Web Vacancies}

Breaugh (2008) believes that if companies engage in online recruitment from websites, the clarity of information concerning vacancies such as pay levels, working hours, job tasks are the most important feature in relation to recruitment.

\subsection{Website Features Affect a Potential Job Applicant Decision}

The relationship between information, organisational brand and attitudes toward website attraction for applicants is argued to be an important area to explore, as website usability, aesthetics, accuracy and richness of job information and organisational information somehow impact viewers' attitudes towards organisational recruitment websites (Allen et al., 2007; Maurer et al., 2007). Furthermore, internet based selection procedures can also have positive impact on perception of company image among potential candidates (Anderson, 2003).

\subsection{Usability and Aesthetics}

Internet is most preferred source to search job (Hosein, 2016), therefore researchers have been investigating how website features affect a potential job applicant decision to apply for a position in the organisation (Gregory et al., 2013). Literature asserts that Job seekers appear to prefer companies with more attractive websites to companies with less attractive websites (Zusman, 2002). Companies Corporate Website uniqueness is judged according to content, aesthetics and design characteristics. "Look and feel" of websites is used with special combination of art graphics and multimedia element (Vassilis et al., 2004). Much work in this area focuses on the usability and aesthetics of the websites themselves using techniques such as content analysis to measure applicants' reaction to websites (Williamson et al., 2003).

\subsection{Advertisement Placement}

Hosein (2016) study reveals that the effectiveness of e-recruitment depends upon advertisement placement where perceived advantages and ease of use have significant impact on candidates' intention to apply.

\subsection{Perceived of Usefulness}

Tong and Sivanand (2005) documented that the jobseeker found e-recruitment gives them perceived of usefulness where website could help jobseeker access anything. Cober et al. (2003) suggest that the utility of interactive tools - such as organizations' recruitment websites - depends on the extent to which their design positively affects user access to valued information (i.e., usefulness). Although usefulness is a perception, as suggested by Agarwal and Venkatesh (2002), it is possible to identify those system features that contribute to a user's perception of website usefulness. Brahmana (2013) 
indicate that practices among online job providers in Indonesia seems to be rigid and boring e-recruitment. Enabling job seekers to complete task more quickly were considered important, therefore usefulness of e-recruitment will give more enjoyment and ease of use. In terms of usefulness, online job providers should stress on the improvement of quality, productivity, and the performance of e-recruitment.

A poorly designed website with insufficient and inaccurate information or a lack of information was found to have a negative impact on the company profile. Therefore, literature suggested that companies should make sure websites are properly planned as it could be detrimental to brand image and an important implications for the subsequent formation of organisational attraction (Gibson \& Swift, 2011; Gregory et al., 2013).

\subsection{Website Features: Employee Pictures, Testimonials, Organizational Policy, and Cultural Values}

Sylvia and Mol (2009) examined 1,360 respondents (United Kingdom, Netherland and Belgium) perception toward web-based procedures in multinational financial organizations. It was also revealed that the features of the website, perceived efficiency, and user friendliness were the most important determinants of applicant satisfaction. With respect to the demographics, it was disclosed that, Belgian and Internet Savvy candidates were more satisfied with the online application procedure.

Braddy et al. (2006) found that website design features such as pictures and employee testimonials, organizational policy statements, cultural values, and other general descriptions such as CEO leadership, size of the organization affected individuals' perceptions of culture. But at the same time it is suggested that there is a need to discover the effects of web-based employee testimonials more fully, as providing employment information through word-of-mouse seemed to attract potential applicants better than through a web-based testimonial (Van Hoye, 2007; Walker et al., 2011).

\subsection{Higher the Service Quality of E-Recruitment, Higher the Satisfaction}

Jansen, Jansen and Spink (2005), focused upon three specific research questions for online job seeking process: how do people search for job-related information on the web? How effective are these searches? And how likely are job seekers to find an appropriate job posting or application? The data used to examine these questions come from job seekers submitting job-related queries to a major web search engine at three points in time over a five-year period. Results of their study indicated that individuals seeking job information generally submitted only one query with several terms and over $45 \%$ of job-seeking queries contained a specific location reference.

Cober et al. (2003) believe the following system feature considerations could be helpful to design a recruitment website that is perceived useful by job applicants: first, a recruitment website should be designed in a way that at any given time, job applicants would be able to determine where they are on the website, where they have been, and where they can go (Neilson, 2000); second, feedback mechanisms for applicants and the availability of response from the website (Palmer, 2002). Therefore organizations must consider the information job seekers require and ensure that it is made easily available (Palmer, 2002).

Huang et al. (2012) research results show that the web service quality and user satisfaction of online recruitment websites are positively correlated, which means that the higher the service quality of online recruitment website perceived by the user is, the higher the satisfaction will be. The research results also show that user satisfaction and perceived risk both have a significant effect on continuance intention, loyalty and word-of-mouth communication. 


\section{Research Methodology}

Reviewing the above literature identify that the use of e-recruitment definitely speeds up, reduce costs, and provide information concerning vacancies, further effectiveness of e-recruitment depends upon advertisement placement, aesthetics elements: combination of appealing colors, fonts, and images (Braddy, 2006). Job seekers appear to prefer companies with more attractive websites features to companies. For job seekers, rigid, structured and boring e-recruitment can be detrimental factor to destroy brand image. Adopting unique way can be a differentiation factor which can have positive impact on users. It requires constant web-improvement, measuring productivity and utilisation of feedback mechanism. It is further noted that usage of technology varies between countries therefore demographical factor need to be investigated in enhancing the online recruitment process based on the users' preference and requirement.

As existing literature indicated that hard navigation, incomplete information, rigid structure and boring website feature can affect users mood and perception regarding corporate brand (Brahmana, 2013; Palmer, 2002; Agarwal \& Venkatesh, 2002; Cober et al., 2003; Huang et al., 2012; Allen et al., 2007). Therefore, this research explore factors to identify that whether big Top Ten Saudi Companies encourage job seekers to find job through their corporate websites.

1) Navigation Career link: Is it easy to locate on main webpage?

2) Job advertised between 30 Sep 2016-11 Nov 2016: Are Companies updating job posting?

3) Nationality or Gender Focus: What is the preference in term of Nationality and Gender for advertised jobs?

4) Information about Advertised Job: Is information about job responsibilities and specification sufficient enough or lacking?

5) Career page provide more information about company: Any further information like mission, vision, values or Saudiazation factor is focused on the career web page.

6) E-application process: If candidate wanted to apply what is the process, required registration or email is provided?

This research investigates the current practice of e-recruitment in Saudi Top Ten Companies listed in Forbes 2016:

1) Financial Companies (Al Rajhi Bank, Samba, Riyadh Bank, Saudi British Bank, Saudi Banque Fransi);

2) Petrochemical (SABIC, Tasnee);

3) Telecommunication (Mobily, Saudi Telecom Company);

4) Energy (Saudi Electricity).

Evaluating Top Ten Companies websites were accessed during 30 Sep 2016 to 11 Nov 2016. Due to the changing nature of web content, limited time was set to follow the web activity. The information obtained from website is stated in Table 1.

Further noted that there is lack of research of using e-recruitment from Middle East perspective, thus the aim of this paper is to identify the current practice of e-recruitment in Saudi Arabia. This paper is not intending to use any existing conceptual model such as Technology Acceptance Model (TAM), reason they have limited variables and require testing on sample.

\section{Findings: Top Ten Forbes Listed Saudi Corporate Website E-Recruitment}

There is not a single research found within Saudi context which could highlight the issues of e-recruitment or encourage individual candidate for using e-recruitment. Therefore this study filling the 
literature gap by exploring some features of e-recruitment such as navigation, information about job, organization culture related information, updated career section frequently, and process of application through website.

\subsection{Navigation Career Link}

Easy navigation, spent less time trying to locate the job condition viewed the hiring company more favourably and willing to apply for the position being advertised (Braddy, 2006). Visitors of a website always want to know where they are, where they have been, and what further information they could get. Additionally, an unclear navigation structure can result in the applicant getting lost and therefore leaving the website before he has been able to find the relevant information. The "Two-Click-Rule" by General Electric focus that it must not take more than two clicks to find the relevant information (Feldman et al., 2002). "Linking Mania" should be avoided, links should be periodically reviewed and availability of tools that support navigation such as labels, buttons, etc. (Vassilis et al., 2004).

While evaluation it shows that out of ten, six Saudi companies have "Career" tab at the bottom of main webpage (Table 1). Placement of link or advertisement matter, therefore another new research avenue that might be stimulated by this study would be to extensively observe with eye tracking, where exactly users' pay attention on the main webpage.

\subsection{Job Advertised between 30 Sep 2016 to 11 Nov 2016}

Stone et al. (2005) advises that job seekers check on frequent bases whether job adverts are updated regularly. According to Table 1, there are three companies which did not advertise any job vacancy. It is noted that Top Ten Forbes listed Saudi Companies updated their job posting except one or two and unfortunately one bank still advertised 2012 jobs on bank website. Furthermore, Utility of Web content can be enhancing by stating the date on which the webpage was last updated (Grose et al., 1998).

\subsection{Nationality or Gender Focus}

According to Saudi National Policy-Saudiazation require a higher level of participation by both male and female equally, however, the most recent statistic indicates that $5.6 \%$ of total labour force is unemployed in Saudi Arabia, including Saudi citizen (20.70 million), expatriates (12.2 million), male (2.4\%) and female (21.4\%) (Arab News, 2016). Such statistics shows that companies need to be proactive in creating job opportunities for Saudi vs. Expat and Male vs. female to utilize manpower on talent and qualification bases. This research finding shows that out of ten, four companies mentioned clearly that they are interested in hiring Saudis however job opportunities for females are rarely found.

\subsection{Information about Advertised Job}

Corporate website content should reflect completeness and reliability by conveying trust worthiness of information: clarity of information concerning vacancies (Vassilis et al., 2004). According to this research finding, two companies provided limited information about job responsibilities and specification (Table 1). Information related to wage, salary, benefits should be disclosed online as compensation rate of the company not only reaches to the candidates but will be known to all.

\subsection{Career Page Provide more Information about Company}

Literature also highlighted that Organization that use corporate career sections can provide prospective applicants with patently superior and necessary information about the organization, its culture, job and career perspectives (Stone et al., 2006; Braddy, 2006). Satisfactorily, it is found that most top ten listed companies' focuses on mission/vision, values. Videos were also found focusing organization values, which is added value (Table 1 ). 


\subsection{E-Application Process}

If the e-application process is delayed, slow or lengthy, pooling right candidates will be difficult or impossible. Literatures assert that Bank of Ireland has evaluated their approach to e-recruitment, largely based upon cost effectiveness, speed to hire and consistency of decision making. Following the implementation of the online system an evaluation found the amount of time saved in term of capturing candidate information was approximately 20 working days, while the time saving of not having to manually score CVs was over 62 working days (Niall \& Martina, 2006). Delays in the application process may cause the loss of the applicants interest or could signal lacking competence of the company (Rynes, 1991). And if the screening process is not well done, the quantity of applications/résumés logged-on can in fact, lengthen the short-listing process (Margaret et al., 2012).

It is a suggestion to Saudi companies to check e-application process as in most cases candidate are required to register sign up first and then fill long online form. Creating favourable candidate perceptions via their online experience at the outset was considered vital, and they made the decision not to introduce automatic screening or "knock out" questions to reduce volumes of applications, and therefore to avoid the risk of jeopardising long term relationships with candidate (Niall \& Martina, 2006). A example of Merrill Lynch will be helpful as they require all applications to complete a brief online application form in addition to attaching their CV. Research carried out by the organisation indicated that application forms should take less than 2 minutes to complete or risks "putting off" candidates. Moreover, E-application long filling process can be substitute by submitting short CV video of 3-5 minute covering main aspect of experience, skills and qualification.

Table 1. Websites Access on 30 Sep 2016 to 11 Nov 2016-Top Ten Saudi Companies Listed in Forbes 2016

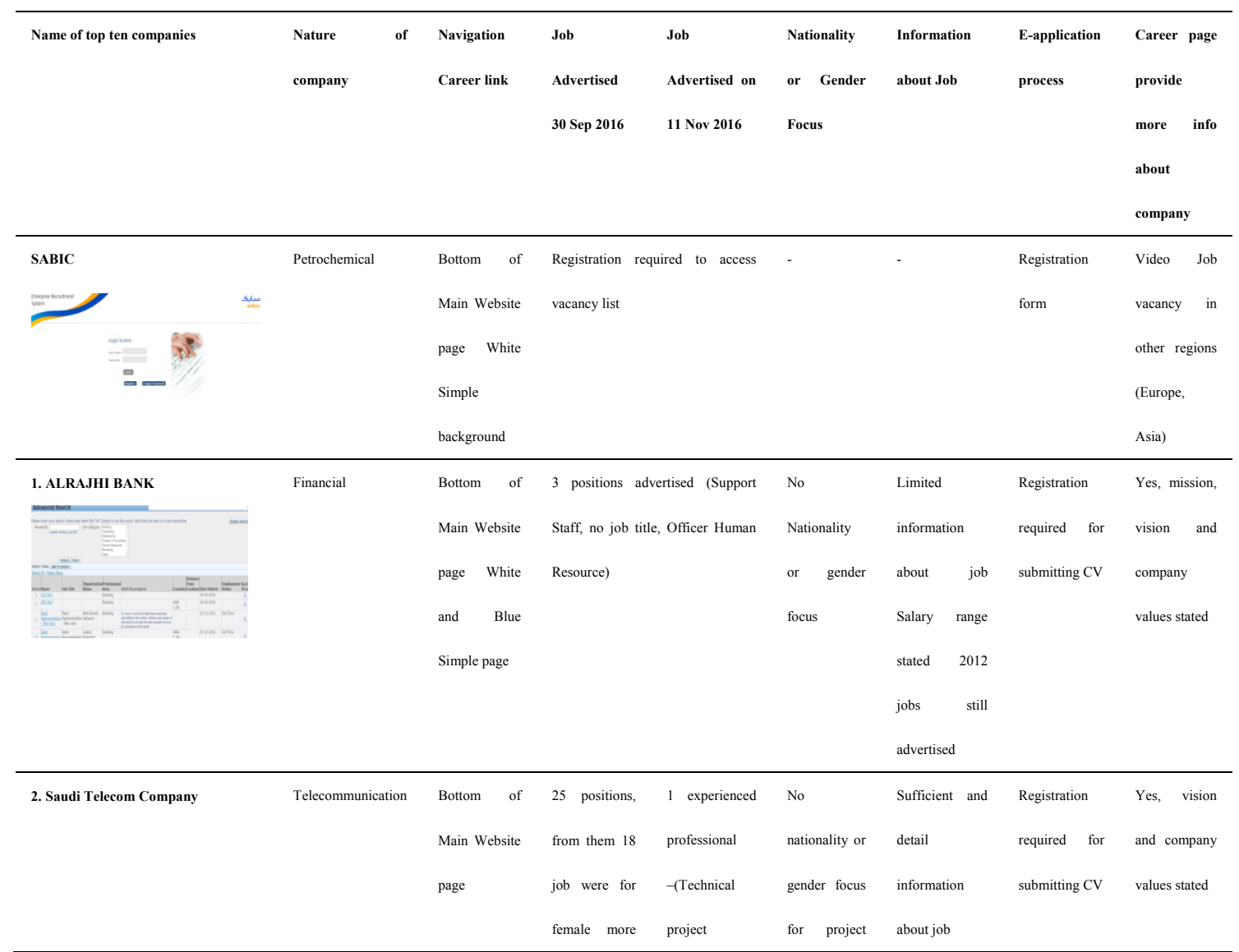




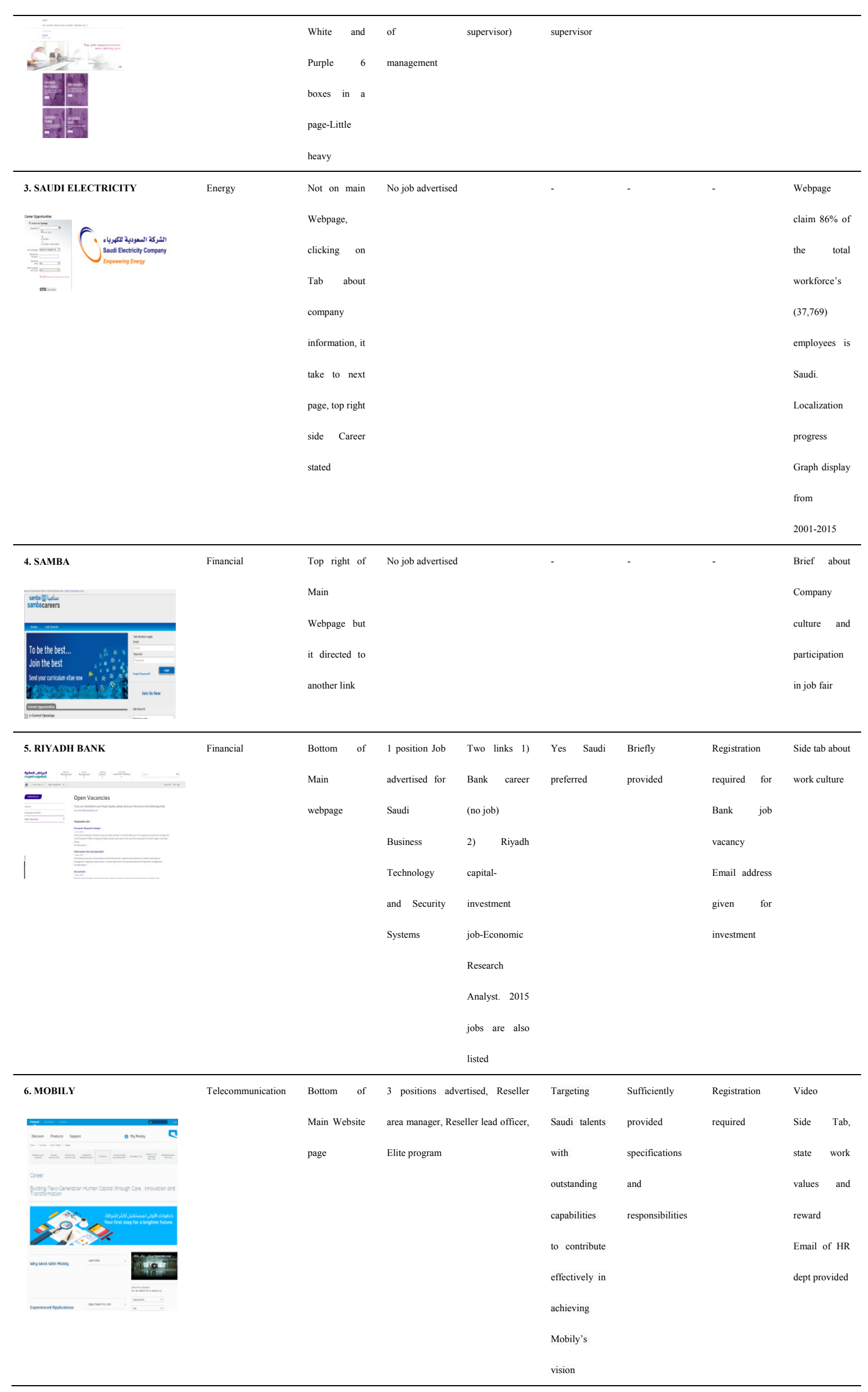




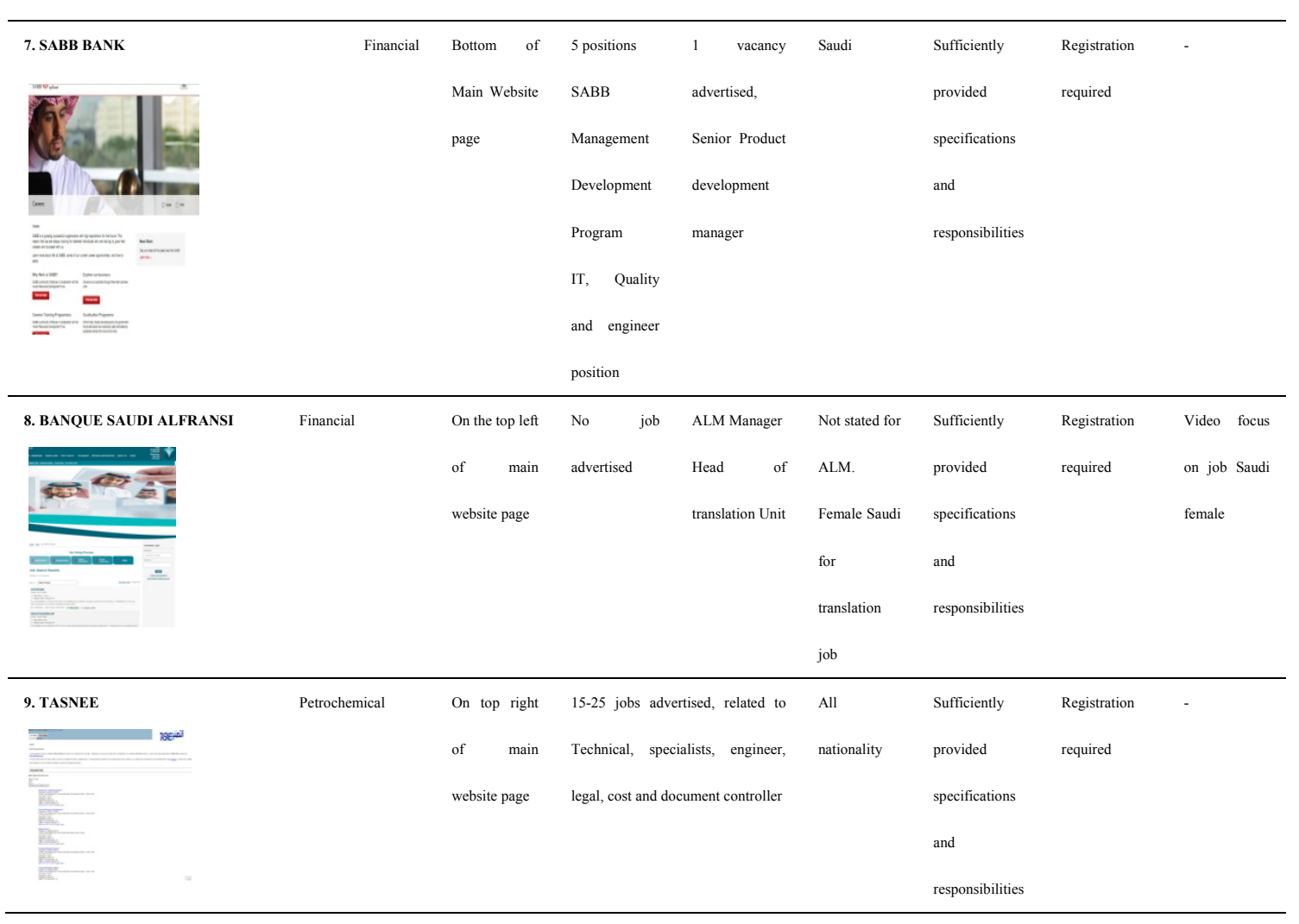

\section{Discussion: Elements to Focus for Empowering and Increasing Usability of E-Recruitment in} Saudi Context

- Understanding attitude of job seekers is a very key element as internet may not be priority for all job seekers (Ferrero \& Vidal, 2001). Literature indicate that usage of technology varies between countries because of demographic and internet users, Saudi companies first need to identify the number and attitude of job seekers Saudis and non-Saudis, male and female who are approaching to corporate website to seek for applying for a position.

- Saudi Companies should update job posting on a frequent bases. Out-dated Job posting (Stone, 2005), will have negative impact on job seekers.

- Differentiation factor of company can be focus on mission/vision, values through highlighting in Texts and Videos.

- Sufficient complete information about job responsibilities and information related to wage, salary, and benefits should be disclosed online.

- Job opportunities for females should be highlighted with skill set required for it.

- Design useful Web features which attract users and easy navigation-When a job seeker is clicking it should lead to main page directly without much of roaming to other links. Eye tracking, will be beneficial to analyse that where exactly users' pay attention on the main webpage if they want to apply for a job.

- The process of registration and CV e-submission should be easy.

- Train HR staff to fix technical issues, CV processing and response management system, as overwhelming response by unsuitable candidate (Margaret et al., 2012), outdated resumes (Sullivan, 1998), no response from company, lengthy short-listing process can slow down e-recruitment process. Therefore require swift short listing process.

- There is a need to review the result periodically, to find loopholes in the e-recruitment process. 
In the presence of e-recruitment strategy, it can ensure each organization to indicate number of Saudi and non-Saudi employees needed in specific sectors to the Saudi Ministry of Labour. Saudi Ministry of Education can help in starting the degree and courses which are in need and demand, and Saudi Chambers of Commerce will support business and economic activity at local scale (AlSulami, 2014).

Such e-database can be shared with relevant ministries to combat the employment issues.

\section{Saudi Companies can advertised their iobs through website}
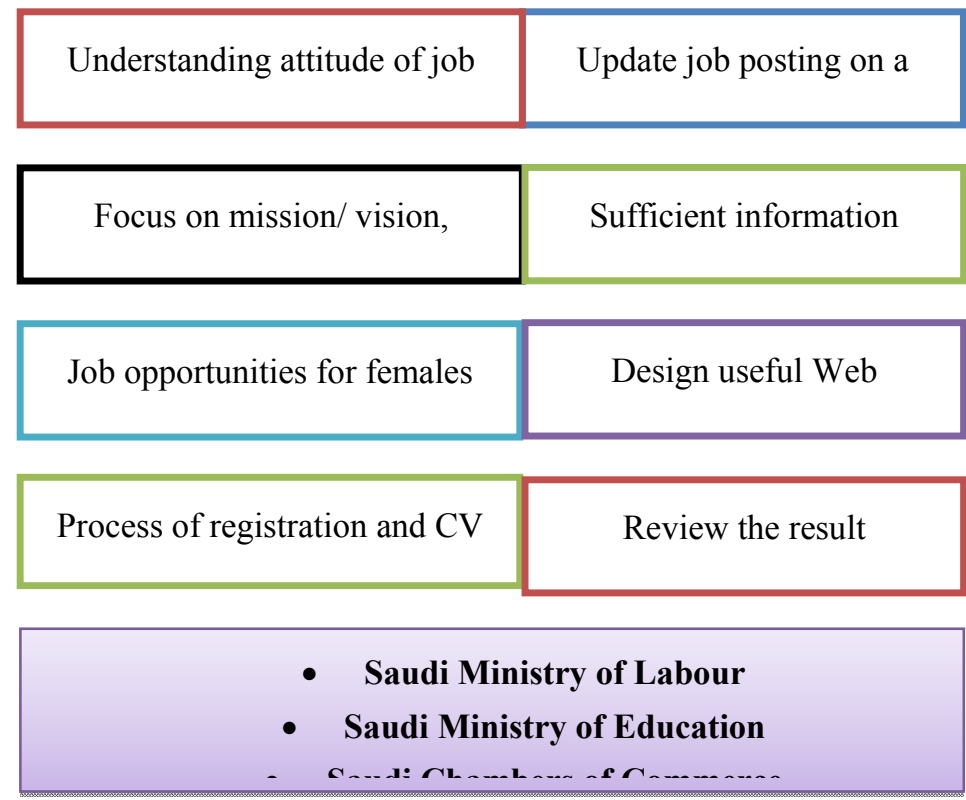

Figure 1. Usability of E-Recruitment in Saudi Context

\section{Conclusion}

Recruitment, acquiring right talent impact most critically on the performance of an organisation, as job market becomes increasingly competitive specifically in Saudi context due to Saudiazation policy. Thus this research believes that the impact of unemployment will be severe if addressing current talent management gap is not a priority of Saudi companies. The paper provides a basis for understanding the trend of online recruitment and issues within Saudi Context. Factors evaluated on company webpage are: navigation career link, Job advertised (updated and information), nationality and gender focus for advertised job, information about company values on career page, process for filling application. Suggestions of this research can help Saudi organisations to develop concrete plan which can enhance online recruitment approach. Due to the quick, efficacy and ease of using company websites, it can be cogently beneficial for job seekers and job providers, therefore organisations are looking for more innovative ways to make e-recruitment practices more effective, efficient, engaging and personal. This in turn may increase the quantity and quality of the applicant base and in the longer term potentially reduces staff turnover. Further research is required from perspective of job seekers in Saudi Arabia to identify the elements which can encourage them to apply through corporate websites. 


\section{References}

Al Asmari, H. (2008). Saudi Labor Force: Challenges and Ambitions. JKAU: Arts \& Humanities, 16(2), 19-59. https://doi.org/10.4197/art.16-2.2

Al Maeena, K. (2016, August 31). Addressing unemployment among Saudi youth. Saudi Gazette, Local Newspaper.

Al Sheikh, \& Hend, M. (2015). Current progress in the nationalisation programmes in Saudi Arabia. Explanatory Note. Gulf Research Center.

Allen, D. G., Mahto, R. V., \& Otondo, R. F. (2007). Web-based recruitment: Effects of information, organizational brand and attitudes towards a web site on applicant attraction. Journal of Applied Psychology, 92(6), 1696-1708. https://doi.org/10.1037/0021-9010.92.6.1696

Anderson, N. (2003). Applicant and Recruiter reaction to new technology in selection: A critical review and agenda for future research. International Journal of Selection and Assessment, 11(2), 121-136. https://doi.org/10.1111/1468-2389.00235

Arab News. (2016, July 20). 680,000 Saudi citizens without jobs in Kingdom.

Bharwani, S., \& Butt, N. (2012). Challenges for the global hospitality industry: An HR perspective. Worldwide Tourism Hospitality $\quad$ Themes, 4(2), 150-162. https://doi.org/10.1108/17554211211217325

Braddy, P. W., Meade, A. W., \& Kroustalis, C. M. (2006). Organizational Recruitment Website effects on viewers' perceptions of Organizational Culture. Journal of Business and Psychology, 20(4), 525-543. https://doi.org/10.1007/s10869-005-9003-4

Brahmana, R. K., \& Rayenda, B. (2013). What Factors Drive Job Seekers Attitude in Using E-Recruitment? South East Asian Journal of Management, 7(2).

Breaugh, J. A. (2008). Employee Recruitment: Current Knowledge and important areas for future research. Human Resource Management Review, 18(1), 103-118. https://doi.org/10.1016/j.hrmr.2008.07.003

Caers, R., \& Castelyns, V. (2011). LinkedIn and Face book in Belgium: The influences and biases of social network sites in recruitment and selection procedures. Social Science Computer Review, 29(4), 437-448. https://doi.org/10.1016/j.hrmr.2008.07.003

Casaló, L., Flavián, C., \& Guinalíu, M. (2008). The role of perceived usability, reputation, satisfaction and consumer familiarity on the website loyalty formation process. Computers in Human Behavior, 24(2), 325-345. https://doi.org/10.1016/j.chb.2007.01.017

Cober, R. T., \& Brown, D. J. (2006). Direct employers association recruiting trends survey. Washington D.C. Retrieved from http:/www.jobcentral.com/DEsurvey.pdf

Cober, R. T., Brown, D. J., \& Levy, P. E. (2004). Form, content and function: An evaluative methodology for corporate websites. Human Resources Management, 43(2/3), 201-218. https://doi.org/10.1002/hrm.20015

Cober, R., Brown, D., Keeping, L., \& Levy, P. (2004). Recruitment on the net: How do organizational website characteristics influence applicant attraction. Journal of Management, 30, 623-646. https://doi.org/10.1016/j.jm.2004.03.001

Feldman, D. C., \& Klaas, B. S. (2002). Internet Job Hunting: A Field Study of Applicant Experiences with On-Line Recruiting. Human Resource Management, 42(2), 175-192. https://doi.org/10.1002/hrm.10030

Gibson, P., \& Swift, J. (2011). e2c: Maximising electronic resources for cruise recruitment. Journal of Hospitality and Tourism Management, 18(1), 61-69. https://doi.org/10.1375/jhtm.18.1.61 
Gregory, C. K., Meade, A. W., \& Foster Thompson, L. (2013). Understanding internet recruitment via signalling theory and the elaboration likelihood model. Computers in Human Behavior, 29(5), 1949-1959. https://doi.org/10.1016/j.chb.2013.04.013

Grensing-Pophal, L. (2004). Credit Union Management. Retrieved from http://www.cumanagement.org

Grose, E., Forsythe, C., \& Ratner, J. (1998). Using Web and traditional style guides to design web interfaces. In Human Factors and Web Development (pp. 121-131). Lawrence Erlbaum Associates. New Jersey.

Hen-Yi, H., \& Chan, P. (2012). Factors Influencing the User Behaviour Intention of Online Recruitment Websites. International Journal of Business and Commerce, 1(9), 107-126.

Hosain, M. D., Sajjad, U., Kazi, T., \& Khudri, M. (2016). The Impact of E-Recruitment on Candidates' Attitudes: A Study on Graduate Job Seekers of Bangladesh. Journal of Human and Social Science Research, 8(1), 009-017.

International Market Report on European Job Sites 2011/2012. (2012). Aktor Interactive's International Job Board Analysis.

Jansen, B. J., Jansen, K. J., \& Spink, A. (2005), Using the Web to Look for Work Implications for Online Job Seeking and Recruiting Internet Research. Journal of Internet Research, 15(1), 49-66. https://doi.org/10.1108/10662240510577068

Kim, S. J. G., \& O’Connor. (2009). Assessing Electronic Recruitment Implementation in State Governments: Issues and Challenges. Public Personnel Management, 38(1), 47-66. https://doi.org/10.1177/009102600903800104

Lee-Won, R. J., Shim, M., Kyoung, Y., \& Gwan Park, S. (2014). Who puts the best; face; forward on Facebook? Positive self-presentation in online social networking and the role of self-consciousness, actual-to-total Friends ration, and culture. Computers in Human behaviour, 39(6), 413-423. https://doi.org/10.1016/j.chb.2014.08.007

Margaret, A., \& Richardson. (2012). Recruitment Strategies: Managing/Effecting the Recruitment Process. Government of the Republic of Trinidad and Tobago, 2(24). Retrieved from http://www.unpan1.un.org/intradoc/groups/public/documents/un/unpan021814.pdf

Maurer, S. D., \& Liu, Y. (2007). Developing effective e-recruiting websites: Insights from managers for marketers. Business Horizons, 50(4), 305-314. https://doi.org/10.1016/j.bushor.2007.01.002

Niall, L., \& Martina, R. (2006). E-Recruitment Practices and trends in Ireland (pp. 4-45). Public Appointments Service-Research Advisory Panel.

Palmer, J. (2002). Website Usability, Design, and Performance Metrics. Information System Research, 13(2), 151-167. https://doi.org/10.1287/isre.13.2.151.88

Peck, J. R. (2014). Can Hiring Quotas Work? The Effect of the Nitaqat Program on the Saudi Private Sector. Working Paper, KACST and MIT. March.

Pin, R., Laorden, M., \& Sáenz-Diez, I. (2001). Internet Recruiting Power: Opportunities and Effectiveness. IESE Research Paper, 439. https://doi.org/10.1111/j.1744-6570.1991.tb02402.x

Rynes, S. L., Bretz, R. D., \& Gerhart, B. (1991). The Importance of Recruitment and Job Choice: A Different Way of Looking. Personnel Psychology, 44(3), 487-521.

Stone, D. L., Lukaszewski, K., \& Isenhour, L. (2005). E-Recruiting: Online strategies for attracting talent. In H. G. Gueutal, \& D. L. Stone (Eds.), The Brave New World of eHR: Human Resources Management in the Digital Age (pp. 54-103). San Francisco. 
Stone, D. L., Stone-Romero, E. F., \& Lukaszewski, K. (2006). Factors affecting the acceptance and effectiveness of electronic human resource systems. Human Resource Management Review, 16(2), 229-244. https://doi.org/10.1016/j.hrmr.2006.03.010

SylvaH, MolST. E-recruitment: A study into applicant perceptions of an online application system. (2009). International Journal of Selection and Assessment, 17(3), 311-323. https://doi.org/10.1111/j.1468-2389.2009.00473.x

Tong, D. Y. K. (2009). A study of e-recruitment technology adoption in Malaysia. Industrial Management \& Data Systems, 109(2), 281-300. https://doi.org/10.1108/02635570910930145

Tussayadiah, I. P., \& Fesenmaier, D. R. (2009). Mediating the tourist experience access to places via shared videos. Annals of Tourism Research, 36(1), 24-40. https://doi.org/10.1016/j.annals.2008.10.001

Van Hoye, G., \& Lievens, F. (2007). Investigating Webbased recruitment sources: Employee testimonials vs word-of-mouse. International Journal of Selection and Assessment, 15(4), 372-382. https://doi.org/10.1111/j.1468-2389.2007.00396.x

Vassilis, M., Charalambos, L., Andreas, D., \& Loukas, T. (2004). Website Quality Assessment Criteria. IQ Conference (pp. 59-73).

Walker, H. J., Field, H. S., Giles, W. F., Bernerth, J. B., \& Short, J. C. (2011). So what do you think of the organization? A contextual priming explanation for recruitment web site characteristics as antecedents of job seekers' organizational image perceptions. Organizational Behavior and Human Decision Processes, 114(2), 165-178. https://doi.org/10.1016/j.obhdp.2010.11.004

Williamson, L. O., Lepak, D. P., \& King, J. (2003). The effect of company recruitment web site orientation on individuals' perceptions of organizational attractiveness. Journal of Vocational Behavior, 63(2), 242-263. https://doi.org/10.1016/S0001-8791(03)00043-5

Zusman, R. R., \& Landis, R. S. (2002). Applicant preferences for Web-based versus traditional job postings. Computers in Human Behavior, 18(3), 285-296. https://doi.org/10.1016/S0747-5632(01)00046-2 